\title{
ANALISA PENERAPAN PELAYANAN OPERASIONAL IT PADA INDUSTRI ELEKTRONIKA DENGAN KONSEP ITIL V3
}

\section{Zulkarnain, Skom, MMSI \\ Universitas Internasional Batam, Indonesia}

\section{INFORMASI ARTIKEL}

\author{
Diterima Redaksi: Agustus, 2021 \\ Diterbitkan Online: September, 2021
}

\section{KATA KUNCI}

Industri Elektronika, ITIL, Pelayanan

Operasional IT

\begin{tabular}{l} 
KORESPONDENSI \\
\hline E-mail: zulbtm@gmail.com
\end{tabular}

\begin{abstract}
A B S T R A C T
Penelitian ini dilakukakun untuk mengetahui sejauh mana penerapan pelayanan operasional IT dalam sebuah industri elektronika dengan konsep ITIL V3. Dalam dunia industri, peranan pelayanan operasional IT sangat dibutuhkan untuk mundukung produktifitas operasional perusahaan. Metode yang digunakan adalah metode deskriftif kuantitatif dengan melakukan wawancara dan observasi secara langsung. Penulis akan melakukan perbandingan penerapan pelayanan IT pada perusahaan, serta mengukur kecepatan team dalam menyelesaikan IT insiden yang terjadi. Perusahaan dapat mengetahui apakah pelayanan operasional IT sudah sesuai dengan konsep dan mengetahui kinerja team IT dalam menyelesaikan IT insiden. Dengan menerapkan konsep ITIL pada pelayanan operasional IT akan memberikan manfaat dan nilai lebih bagi perusahaan.
\end{abstract}

\section{Latar Belakang}

Perkembangan teknologi IT sangat cepat dan hampir semua perusahaan memanfaatkan teknologi tersebut untuk mendukung kegiatan operasional perusahaan. Untuk mendapatkan pelayanan IT yang baik, diperlukan tata kelola agar pelayanan IT dapat memberikan manfaat.

Banyak konsep yang bisa diadopsi dalam penerapan pelayanan IT ini, seperti konsep ITIL V3. Salah satu pelayanan IT yang menjadi focus perusahaan adalah terkait dengan tata kelola pelayanan IT insiden. Perusahaan menginginkan agar pelayanan IT insiden harus dilakukan dengan benar. Khususnya insiden yang berkaitan dengan proses bisnis.
Team IT harus mampu mengelola insiden dengan baik, dan dapat melakukan respon dengan cepat, yang disesuaikan dengan tingat keperluan dan dampak dari insiden tersebut terhadap operasional perusahaan.

Hal ini menjadi menarik bagi penulis untuk melakukan penelitian berdasarkan data yang ada saat ini terkait dengan pelayanan insiden pada perusahaan. Penulis ingin mendapatkan gambaran sejauh mana tingkat efektifitas tim IT dalam memberikan pelayanan dengan konsep ITIL 3.

Penulis melakukan penelitian pada sebuah perusahaan perakitan elektronika yang berada di Batamindo Industrial Park, Pulau Batam. Perusahaan ini mempunyai lebih dari 1000 
komputer dan mempunyai insiden yang sangat dinamis.

Penulis akan mengambil data langsung melalui team IT dan selanjutnya akan melakukan pengolahan berdasarkan konsep ITIL V3. Dari laporan ini semoga dapat memberikan gambaran terkait dengan pelayanan IT saat ini , apakah sudah dilakukan dengan benar dan perusahaan mendapatakn visibilitas yang tinggi terkait dengan pelayanan yang berjalan saat ini.

Dengan memperhatikan latar belakang yang ada, bagaimana kita bisa mengetahui pelayanan yang dilakukan dengan konsep ITIL V3 dapat berdampak kepada pelayanan yang efektif dan efesien, serta dapat memberikan visibilitas kita bagi perusahaan terkait dengan pelayanan IT saat ini.

Adapun tujuan dari penelitian yang dilakukan penulis adalah untuk mencari tahu beberapa hal, terkait dengan pelayanan IT operation di perusahaan sebagai berikut. Penulis ingin mendapatkan informasi terkait dengan pelayanan IT dengan konsep ITIL apakah sudah dilakukan dengan benar sehingga dapat memberikan manfaat dan nilai tambah bagi perusahaan.

\section{Kajian Literatur}

Information Technology Infrastructure Library atau disebut juga dengan istilaha ITIL adalah sebuah model atau konsep atau praktek terbaik yang digunakan untuk mengelola teknologi informasi infrastruktur pada suatu perusahaan. Metode yang dilakukan dengan melakukan penyelarasan antara pelayanan IT dengan kebutuhan bisnis.

ITIL juga memberikan cara kepada kita agar bisa mengelola IT dengan basis pelayanan. Apabila penerapan ITIL dilakukan dengan benar, tentunya dapat memberikan manfaat secara optimal. Diantara manfaat ITIL bagi perusahaan adalah sebagai berikut :

1. Pengelolaan ITIL dapat mengurangi biaya serta dapat mempercepat kembalinya ROI

2. Kepuasan pengguna IT dapat semakin meningkat dengan menerapkan konsep ITIL

3. Meningkatkan produktifitas pelayanan IT, dengan memberikan pelayanan yang efektif dan efesien

4. Mengoptimalkan pemanfaatan penggunaan aset
5. Mendorong organisasi untuk terus berkembang mengikuti perkembangan teknologi terkini.

Konsep ITIL menempati posisi 5 tata kelola terbaik yang dilakukan survey pada tahun 2011 . Pada mulanya, ITIL merupakan bentuk pedoman pelayanan IT yang terdiri dari dua puluh enam modul. Awalnya ITIL dikeluarkan sekitar tahun 2000 sampai 2004. ITIL pertama ini dipicu oleh usaha untuk meningkatkan pelayanan yang berkesinambungan dan kecepatan dalam beradaptasi terhadap lingkungan baru. Kemudian ITIL V3 diterbitkan pada tahun 2007 oleh OGC (Office of Government Commerce).

ITIL memiliki 5 framework utama dengan prinsip prinsip sepert Service Strategy, Service Design, Service Transition, Service Operation, Continual Service Improvement.

Yang dimaksud dengan service strategy atau strategy layanan adalah bagaimana menjadikan asset manegement menjadi model aset yang stategis.

Untuk service design adalah bagaimana melakukan perancangan layanan IT agar dapat menjamin tingkat kepuasan pelanggan atau penggunaa IT. Sedangkan service transition adalah kemampuan mengelola proses transisi dari sistem lama ke system yang baru tanpa mengurangi kualitas deri pelyanan IT. Service operation adalah model pengelolaan layanan kepada pengguna dengan cara yang efektif dan efesien. Pada tahapan ini, pelanggan mendapatkan manfaat dari pelayanan IT sehingga mereka merasa puas dari pelayanan IT yang diberikan. Prinsip yang terakhir adalah continual service improvement, yaitu usaha untuk terus mempertahankan nilai yang baik bagi pelanggan dan juga melakukan perbaikan jika ada hal yang harus diperbaiki.

Dalam terminologi ITIL, insiden adalah interupsi yang terjadi ada pelayanan IT atau berkurangnya kualitas pelayanan, atau terjadi kerusakaan yang mengakibatkan pelayanan IT tidak bisa digunakan oleh pengguna.

Manajemen insiden adalah tata kelola insiden, mulai dari siapa orang yang akan menghandel insiden tersebut, bagaimana IT bisa mendeteksi insiden, bagaimana monitoring dan juga model komunikasi yang bisa dilakukan untuk memberitahu adanya insiden tersebut.

Ada beberapa proses dalam melakukan tata kelola pelayanan IT insiden. 
Berawal dari adanya tata kelola event manajemen. Event manajemen penting dalam proses pelayanan IT. Pesan tampilan dalam bentuk informasi, peringatan atau terjadi hal yang tidak wajar sehingga tim IT dapat mengambil tindakan yang diperlukan.

Setelah event manajemen, ada juga proses insiden manajemen. Dalam insiden manajemen ini, tim IT akan mengembalikan layanan yang mengalami masalah agar dapat kembali berfungsi dengan baik. Ada beberapa kegiatan terkait dengan insiden manajemen ini, mulai dari adanya identifikasi masalah, pencatatan masalah yang terjadi, melakukan kategori insiden yang terjadi, membuat prioritas dan hal - hal lain yang terkait dengan insiden manajemen.

Insiden IT yang terjadi sebaiknya dianalisa dan diselesaikan apa yang menjadi akar permasalahan dari insiden tersebut. Disini kita memerlukan Problem manajemen, apakah analisa dilakukan secara reaktif atau proaktif. Dengan memahami akar permasalahan, tim IT akan lebih mudah untuk melakukan perencanaan tindakan pencegahan. Agar insiden tidak terjadi lagi dikemudian hari.

Focus berikutnya adalah terkait dengan access manajemen. Hak akses harus dikelola dengan benar, mulai dari adanya prosedur terkait dengan permintaan hak akses, kemudian tim melakukan verifikasi, jika memang benar maka akan diberikan hak akses, melakukan pengawasan dan dapat mencabut hak ases jika diperlukan. Dan yang terpenting adalah bisa melakukan penelusuran akses terkait dengan proses audit.

\section{Metodologi}

Penelitian dilakukan disebuah perusahaan di batamindo industrial park, yang berada di pulau Batam. Perusahaan tersebut bergerak dalam industri perakitan elektronika, dan mempunyai lebih dari 500 karyawan. Tempat ini penulis jadikan sebagai populasi untuk mengambil data. Data yang diambil melalui wawancara dengan tim IT dan juga mengambil data dari database perusahan tersebut.

Metode yang digunakan penulis adalalah menggunakan metode deskriptif, dimana penulis akan memberikan gambaran dari sesuatu keadaan, dalam hal ini penulis mendeskripsikan fakta yang ada pada operasional pelayanan IT pada sebuah perusahaan yang bergerak dalam industri perakitan elektronika.

Perusahaan tersebut menggunakan system berskala IT enterprise. Seluruh proses produksi didukung oleh perangkat IT, mulai dari komputer, jaringan, server, database hingga aplikasinya. Data yang diambil, kemudian dikumpulkan untuk diolah, selanjutnyua dilakukan analisa.

Adapun tahapan dalam penulisan ini sebagai berikut :

1. Mengidentifikasi obyek penelitian

2. Membuat latar belakang, rumusan masalah dan tujuan penelitian

3. Melakukan studi pustaka yang berkaitan dengan penelitian

4. Mendesain metode penelitian, menentukan populasi

5. Pengambilan dan Pengumpulan data

6. Pengolahan dan analisa data

7. Kesimpulan

Pada tahapan pertama, penulis mengindentifikasi obyek penelitian, yaitu perusahaan industri perakitan elektronik yang ada di kawasan industri batamindo, pulau Batam. Perusahaan ini penulis pilih karena telah menggunakan IT sistem yang baik dan mempunyai lebih dari 500 komputer yang digunakan untuk mendukung kegiatan bisnisnya.

Tahapan kedua penulis melakukan studi pendahuluan, dengan memahami latar belakang tentang penulisan ini dan dilanjutkan dengan menentukan tujuan penelitian.

Tahapan ketiga, mempelajari teori yang berkaitan dengan penelitian.

Tahapan keempat adalah mendesian model penelitian yang dilakukan serta menentukan secara khusus populasi data yang akan diambil

Tahapan kelima adalah melakukan pengambilan data secara langsung, melalui wawancara dengan team IT dan juga mengambil data dari database yang tersedia.

Dalam melakukan pengambilan data, penulis focus dalam beberapa sebagai berikut :

Dalam pengambilan data, penulis akan melakukan identifikasi, melihat catatan penting terkait insiden, bagiamana proses kategori insiden, melakukan prioritas, proses eskalasi sampai kepada proses penutupan insiden. Adapun topic yang akan diangkat seputar hal : 
1. Event Management

2. Incident Management

3. Problem Management

4. Access Management

Tahapan keenam, melakukan analisa berdasarkan data yang sudah diolah.

Tahapan ketujuh adalah membuat kesimpulan dari penelitian.

Banyak manfaat dan kemudahan yang penulis dapatkan dengan menggunakan metode deskriftif. Peneliti focus pada pelayanan yang pada tahun berjalan. Peneiliti mengambil data dan kemundian menuliskan dan mendeskripsikan apa adanya.

\section{Pembahasan}

\section{Event Management}

Dalam proses IT Operation, Event Manajemen merupakan hal pertama yang menjadi perhatian. Penulis mencari data yang berkaitan dengan perubahaan apa saja yang dikontrol, apakah ada SLA serta ketika terjadi perubahaan, apakah ada yang sesuatu yang dilakukan agar tim IT mendapatkan notifikasi.

Dalam event manajemen ini, penulis mengambil data untuk dianalisa dalam table berikut.

\begin{tabular}{|l|l|l|c|}
\hline IT Service & Kontrol & Notifikasi & $\begin{array}{c}\text { Rating } \\
\text { (1=poor, } \\
2=\text { fair, } \\
3=\text { good, } \\
4=\text { excellent })\end{array}$ \\
\hline $\begin{array}{l}\text { Windows Server } \\
\text { Availability }\end{array}$ & $\begin{array}{l}\text { Uptime and } \\
\text { Downtime }\end{array}$ & $\begin{array}{l}\text { Email will be } \\
\text { send any } \\
\text { unplanned server } \\
\text { downtime }\end{array}$ & 4 \\
\hline CPU usage & $\begin{array}{l}\text { Utilization reach } \\
\text { to 80\% }\end{array}$ & $\begin{array}{l}\text { Email will be } \\
\text { send if cpu usage } \\
\text { more than } 80 \%\end{array}$ & 4 \\
\hline Memory Usage & $\begin{array}{l}\text { Utilization reach } \\
\text { to 80\% }\end{array}$ & $\begin{array}{l}\text { Email will be } \\
\text { send if memory } \\
\text { usage more than } \\
80 \%\end{array}$ & 4 \\
\hline $\begin{array}{l}\text { UPS Running } \\
\text { without power }\end{array}$ & $\begin{array}{l}\text { No electric power } \\
\text { to UPS }\end{array}$ & $\begin{array}{l}\text { Email will be } \\
\text { send if UPS } \\
\text { running without } \\
\text { electric power }\end{array}$ & \\
\hline WAN Down & $\begin{array}{l}\text { No Internet } \\
\text { Access }\end{array}$ & $\begin{array}{l}\text { Central Help } \\
\text { Desk will notice if } \\
\text { WAN connection } \\
\text { down }\end{array}$ & \\
\hline $\begin{array}{l}\text { Fire Safety in Data } \\
\text { Center }\end{array}$ & $\begin{array}{l}\text { FM200 fire } \\
\text { suppression } \\
\text { system }\end{array}$ & $\begin{array}{l}\text { FM Staff will } \\
\text { notice IT team }\end{array}$ & 2 \\
\hline
\end{tabular}

Tabel 1. Rating Event Managemen

\section{Incident Management}

Proses kedua yang dilakukan penulis adalah dengan menganalisa tata kelola penanganan IT insiden yang terjadi. Ada beberapa hal yang menjadi focus peneliti untuk menganalisa proses ini. Mulai dari melihat metode yang digunakan untuk menangani insiden, adanya status yang jelas terhadap insiden yang terjadi sampai pada bagaimana menentukan prioritas terhadap insiden yang terjadi.

\begin{tabular}{|c|c|c|}
\hline $\begin{array}{l}\text { Paramater terkait } \\
\text { dengan Insiden } \\
\text { Manajemen }\end{array}$ & Hasil & $\begin{array}{c}\text { Rating ( } 1=\text { poor, } \\
2=\text { fair, } 3=\text { good, } \\
4=\text { excellent })\end{array}$ \\
\hline $\begin{array}{l}\text { Apakah ada ketentuan } \\
\text { persetujuan terkait } \\
\text { dengan SLA (service } \\
\text { level agreement) }\end{array}$ & $\begin{array}{l}\text { Adanya persetujuan } \\
\text { bahwa insident dibagi } \\
\text { dalam beberapa SLA } \\
\text { seperti insiden dnegan } \\
\text { status high harus } \\
\text { diselesaikan dalam } \\
\text { waktu } 8 \text { jam, untuk } \\
\text { status medium } 3 \text { hari } \\
\text { serta low harus } \\
\text { diselesaikan dalam } \\
\text { waktu } 10 \text { hari }\end{array}$ & 3 \\
\hline $\begin{array}{l}\text { Apakah ada status } \\
\text { tracking dari insiden } \\
\text { yang terjadi }\end{array}$ & $\begin{array}{l}\text { Perusahaan } \\
\text { menggunakan } 4 \text { status } \\
\text { dalam insiden, yang } \\
\text { pertama adalah open, } \\
\text { dimana telah tercatat } \\
\text { insiden yang terjadi } \\
\text { namun insiden belum } \\
\text { diberikan ke tim terkait. } \\
\text { Status kedua adalah } \\
\text { inprogress dimana } \\
\text { insiden sudah diketahui } \\
\text { oleh tim yang akan } \\
\text { mengerjakan. Kemudian } \\
\text { ada status resolved, } \\
\text { dimana pada status ini } \\
\text { insiden berhasil } \\
\text { diselesaikan namun } \\
\text { belum dikonfirmasi oleh } \\
\text { user, dan terakhir adalah } \\
\text { status closed, dimana } \\
\text { user menyetujui bahwa } \\
\text { insiden telah berhasil } \\
\text { diselesaikan atau service } \\
\text { kembali dalam kondisi } \\
\text { normal }\end{array}$ & 4 \\
\hline $\begin{array}{l}\text { Apakah data IT In siden } \\
\text { dicatat dan disimpan } \\
\text { dengan benar? }\end{array}$ & $\begin{array}{l}\text { Data insiden tercatat } \\
\text { dengan baik, mulai dari } \\
\text { nomor insiden, tingkat } \\
\text { urgensi, prioritas, waktu } \\
\text { insiden, nama pelapor, } \\
\text { deskripsi insiden, siapa } \\
\text { yang menangani, status } \\
\text { dan informasi lainnya. }\end{array}$ & 4 \\
\hline
\end{tabular}

Tabel 2. Rating Insiden Managemen

\section{Problem Management}

Pembahasan dalam problem manajemen adalah terkait dengan bagaimana kita melakukan tata kelola agar insiden tidak terulang kembali lagi dan bagaimana meminimalisir impak yang terjadi jika insiden tidak bisa di cegah. Berikut hal - hal terkait dengan problem manajemen yang penulis lakukan. 


\begin{tabular}{|c|c|c|}
\hline $\begin{array}{l}\text { Parameter terkait } \\
\text { dengan problem } \\
\text { manejemen }\end{array}$ & Hasil & $\begin{array}{c}\text { Rating ( } 1=\text { poor, } \\
2=\text { fair, } 3=\text { good, } \\
4=\text { excellent })\end{array}$ \\
\hline $\begin{array}{l}\text { Apakah ada kegiatan } \\
\text { terkait dengan deteksi } \\
\text { insiden yang akan } \\
\text { timbul }\end{array}$ & $\begin{array}{l}\text { Perusahaan mempunyai } \\
\text { monitoring system yang } \\
\text { digunakan untuk } \\
\text { memonitor stabilitas } \\
\text { system, jika terjadi } \\
\text { pengurangan kualitas, } \\
\text { maka monitoring system } \\
\text { akan memberikani } \\
\text { notifikasi kepada team it }\end{array}$ & 4 \\
\hline $\begin{array}{l}\text { Tool yang digun akan } \\
\text { untuk melakukan } \\
\text { analisa problem }\end{array}$ & $\begin{array}{l}\text { Perusahaan } \\
\text { menggunakan metode 8D } \\
\text { repot yang digunakan } \\
\text { untuk melakukan analsia } \\
\text { terhadap problem yang } \\
\text { terjadi. Dengan 8D repot, } \\
\text { kita dapat mengetahui } \\
\text { dengan jelas terkait } \\
\text { informasi project } \\
\text { statement, penyebab } \\
\text { problem dan juga } \\
\text { tindakan pencegahannya. }\end{array}$ & 3 \\
\hline $\begin{array}{l}\text { Apakah ada proses } \\
\text { eskalasi jika insiden } \\
\text { yang terjadi melebihi } \\
\text { dari SLA? }\end{array}$ & $\begin{array}{l}\text { Apabila insiden yang } \\
\text { terjadi tidak diselesaikan } \\
\text { dalam watu yang telah } \\
\text { ditentukan, maka ada } \\
\text { team yang akan } \\
\text { melakukan eskalasi ke } \\
\text { level yang lebih tinggi . }\end{array}$ & 3 \\
\hline
\end{tabular}

Tabel 3. Rating Problem Managemen

\section{Access Management}

Tata kelola akses menjadi merupakan hal yang sangat penting, hal ini terkait dengan hak akses pengguna untuk terhubung dengan system IT. Hak akses hanya diberikan kepada pengguna yang memerlukan informasi tersebut.

\begin{tabular}{|c|c|c|}
\hline \begin{tabular}{|l|} 
Parameter terkait \\
dengan access \\
manejemen \\
\end{tabular} & Hasil & $\begin{array}{c}\text { Rating ( } 1=\text { poor, } \\
2=\text { fair, } 3=\text { good, } \\
4=\text { excellent })\end{array}$ \\
\hline $\begin{array}{l}\text { Apakah permintaan } \\
\text { akses dilakukan dengan } \\
\text { process yang tertulis }\end{array}$ & $\begin{array}{l}\text { Perusahaan mempunyai } \\
\text { prosedur yang } \\
\text { digunakan untuk } \\
\text { melakukan permintaan } \\
\text { dari user terhadap akses } \\
\text { sistem terte ntu. }\end{array}$ & 2 \\
\hline $\begin{array}{l}\text { Apakah ada ownership } \\
\text { dari setiap service yang } \\
\text { ada }\end{array}$ & $\begin{array}{l}\text { Team IT telah membuat } \\
\text { list pelayanan atau } \\
\text { aplikasi yang disertai } \\
\text { dengan nama orang } \\
\text { yang bertannggung } \\
\text { jawab untuk } \\
\text { memastikan pelayanan } \\
\text { tersebut bisa digunakan. } \\
\text { Dan juga melakukan } \\
\text { perbaikan jika terja di } \\
\text { gangguan pada service } \\
\text { tersebut. }\end{array}$ & 4 \\
\hline $\begin{array}{l}\text { Adanya audit secara } \\
\text { terkait dengan akses } \\
\text { managejemen ini }\end{array}$ & $\begin{array}{l}\text { Team audit dari kantor } \\
\text { pusat melakukan audit } \\
\text { terkait dengan tata } \\
\text { kelola akses. Hal ini } \\
\text { berkaitan dengan } \\
\text { apakah yang yang } \\
\text { diberikan akses masih } \\
\text { bekerja pada perus ahaa } \\
\text { ini. Jika sudah keluar } \\
\text { maka kita harus } \\
\text { membatasi akses } \\
\text { tersebut. }\end{array}$ & 3 \\
\hline
\end{tabular}

Tabel 4. Rating Access Managemen

\section{Kesimpulan}

Berdasarkan dari data yang kami analisa, kami dapat mengambil kesimpulan dan saran bahwa operasional yang dilakukan sudah mengadopsi konsep ITIL V3. Tim IT membuat prosedur dalam menjalankan pelayanan IT, mulai dari event manajemen, insiden managemen, problem managment dan access manajemen.

Namun demikian, ada beberapa hal yang harus diperbaiki, diantaranya adalah :

1. Melakukan perbaikan infrastruktur pada sumber listrik dan juga melakukan pemasangan jaringan backup untuk internet.

2. Service Level Agreement harus dikomunikasikan secara efektif, terutama kepada key user.

3. Masih banyak permintaan user yang tidak mengikuti prosedur, tim IT harus berusahaan untuk melakukan komunikasi yang efektif kepada user

\section{Ucapan Terima Kasih}

Silahkan ucapkan terimakasih kepada pihak yang membantu dalam penelitian.

Kami mengucapkan terima kasih yang sebesar - besarnya atas dukungan dari segenap manajemen Universitas Internasional Batam, Kaprodi dan Kajur Sistem Informasi UIB, Manajemen SIM LPPM UIB serta Manajemen Jurnal CBIS dari Universitas Putra Batam.

\section{Daftar Pustaka}

[1] R. Steinberg, Service Operation ITIL V3, UK: ITIL Official Publisher, 2011.

[2] I. Prof. Dr. Agustinus Purna Irawan, Perancangan \& Pengembangan Produk Manufaktur, Bandung: Andi Publisher, 2017.

[3] D. Mardiana and W. Cholil, "Analisis Information Technology Service Management (ITSM) LPSE Kota Palembang Berdasarkan Framework ITIL V3," Jurnal Intelektualita, vol. 9, no. 2020, p. $1,2020$.

[4] T. S. U. Manurung, Murahartawaty and R. Hanaf, "ANALISIS DAN PERANCANGAN ITSM DOMAIN SERVICE DESIGN PADA LAYANAN AKADEMIK IPDN," e-Proceeding of Engineering, vol. 2, no. 2, p. 1, 2015. 
[5] I. Maita and S. Akmal, "ANALISIS TATA KELOLA TEKNOLOGI INFORMASI DENGAN BEST PRACTICE ITIL V3 SERVICE OPERATION," Jurnal Rekayasa dan Manajemen Sistem Informasi, vol. 2, no. 1, p. 1, 2016.

[6] I. Maita and S. Akmal, "ANALISIS TATA KELOLA TEKNOLOGI INFORMASI DENGAN BEST PRACTICE ITIL V3," Jurnal Rekayasa dan Manajemen Sistem Informasi, vol. 2, no. 1, p. 1, 2016.

[7] D. I. S. M.Kom, Rekayasa Sistem Manufaktur, Jakarta: Mitra Wacana, 2016.
[8] R. Huang and I. Ngadijaya, "Analisa Tata Kelola Teknologi Informasi pada PT. BJMS," INFORMATICS ENGINEERING RESEARCH AND TECHNOLOGY, vol. 1, no. 1, p. 1, 2019.

[9] D. Herlinudinkhaji, "Evaluasi Layanan Teknologi Informasi ITIL Versi 3," Walisongo Journal of Information Technology, vol. 1, no. 2019, p. 1, 2019.

[10] Heizer, Jay and B. Render, Manajemen Operasi, Jakarta: Salemba Empat, 2014.

[11] S. Assauri, Manajemen Operasi Produksi, Jakarta: Rajawali Pers, 2016. 